
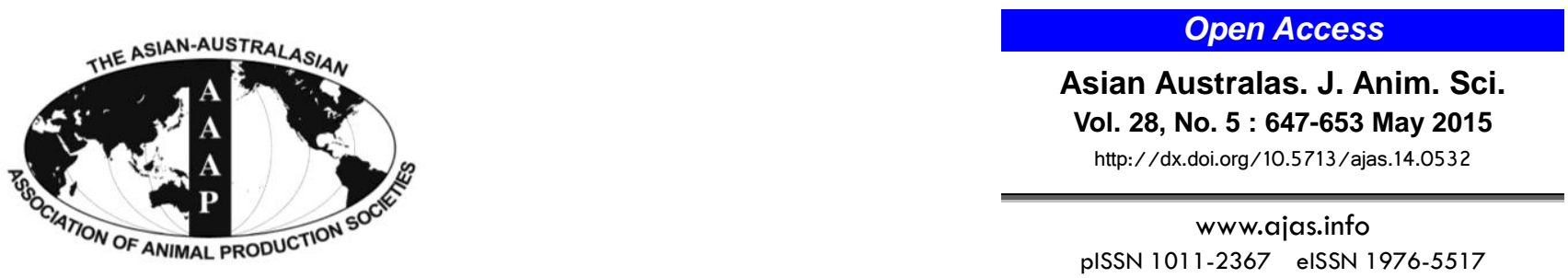

\title{
Choline Essentiality and Its Requirement in Diets for Juvenile Parrot Fish (Oplegnathus fasciatus)
}

\author{
Sanaz Khosravi, Ji-Woong Jang, Samad Rahimnejad, Jin-Woo Song, and Kyeong-Jun Lee* \\ Department of Marine Life Science, Jeju National University, Jeju 690-756, Korea
}

\begin{abstract}
A 12-wk feeding trial was conducted to evaluate the essentiality of choline supplementation in diets for parrot fish. Five isonitrogenous and isocaloric diets were supplemented with 0 (as control), 500, 1,000, and 2,000 $\mathrm{mg}$ choline per kg diet, and a positive control diet without choline contained $0.3 \%$ of 2-amino-2-methyl-1-propanol as choline biosynthesis inhibitor (designated as Con, C500, $\mathrm{C} 1000, \mathrm{C} 2000$ and $\mathrm{Con}^{+}$, respectively). Triplicate groups of fish (body weight, $8.8 \pm 0.01 \mathrm{~g}$ ) were fed one of the experimental diets at a rate of $4 \%$ body weight twice daily. The fish fed $\mathrm{Con}^{+}$diet revealed significantly lower growth performance and feed utilization efficiency than other fish groups. Supplementation of choline to the basal diet did not significantly influence fish growth. The highest liver lipid content was observed in fish fed the $\mathrm{Con}^{+}$diet and inversely correlated with liver choline concentration although the differences were not significant. Also, significantly higher liver linoleic, eicosapentaenoic and docosahexaenoic acid contents were found in fish fed the $\mathrm{Con}^{+}$diet. Innate immune parameters including respiratory burst and myeloperoxidase activities were not significantly affected by dietary choline levels. The findings in this study conclude that choline concentration of approximately $230 \mathrm{mg}$ $\mathrm{kg}^{-1}$ diet meets the requirement of parrot fish. (Key Words: Choline, Parrot Fish, Oplegnathus fasciatus, Growth Performance, Requirement)
\end{abstract}

\section{INTRODUCTION}

Choline is an essential component of cell structure and plays important roles in cell maintenance and certain metabolic functions (McDowell, 2000). It mostly exists in the forms of phospholipids phosphatidylcholine (lecithin), lysophosphatidylcholine, choline plasmalogens and sphingomyelin, and is widely distributed in all plant and animal cells (Zeisel, 1990). It is also an essential component of acetylcholine, the most common neurotransmitter in the nervous system, which is involved in transmission of nerve impulses across synapses (Wauben and Wainwright, 1999). The prominent structural feature of choline is its biologically active methyl groups, through which plays a vital role as a methyl donor in synthesis of various methylated metabolites (Combs, 1992). Furthermore, choline is considered as a lipotropic factor preventing

\footnotetext{
* Corresponding Author: Kyeong-Jun Lee. Tel: +82-64-754-3423, Fax: +82-64-756 3493, E-mail: kjlee@jejunu.ac.kr

Submitted Jul. 17, 2014; Revised Oct. 22, 2014; Accepted Nov. 23, 2014
}

abnormal accumulation of lipid and development of fatty livers (Halver, 2002).

From another point of view, choline is a vitamine-like nutrient and is regarded as an essential dietary component for most young vertebrates (NRC, 2011) including fish; nevertheless it can be synthesized in liver from other methyl donors such as methionine. Most animals can synthesize choline through the methylation of phosphatidylethanolamine mediated by phosphatidylethanolamine- $N$ methyltransferase (PEMT) (McDowell, 2000). The PEMT catalyzes the methylation of phosphatidylethanolamine to form phosphatidylcholine (PC) and represents one of the two major pathways for PC biosynthesis. However, it is believed that the rate of de novo choline synthesis is not sufficient or rapid enough to meet the metabolic requirement of animal including juvenile fishes when the diet is deficient in methyl group donors (Wilson and Poe, 1988).

The signs of choline deficiency including growth retardation, poor survival, poor feed efficiency (FE) and increased liver lipid concentration have been reported in 
carp (Cyprinus carpio) (Ogino et al., 1970), lake trout (Salvelinus namaycush) (Ketola, 1976), rainbow trout (Oncorhynchus mykiss) (Rumsey, 1991), hybrid striped bass (More saxatilis $\times$ Morone chryso) (Griffin et al., 1994), red drum (Sciaenops ocellatus) (Craig and Gatlin, 1996), yellow perch (Perca flavescens) (Twibell and Brown, 2000), channel catfish (Ictalurus punctatus) (Zhang and Wilson, 1999), hybrid tilapia (Oreochromis niloticus $\times$ O. aureus) (Shiau and Lo, 2000) and cobia (Rachycentron canadum) (Mai et al., 2009). Dietary choline requirement has been estimated for several fish species and the value has been reported to be at the range of 400 to $1,000 \mathrm{mg} / \mathrm{kg}$ diet.

Parrot fish is a carnivorous species and is regarded as an emerging aquaculture species due to its high economic value, excellent flesh quality and diseases resistance. However, there are just a few available studies on nutrient requirement of the species (Wang et al., 2003; Nam et al., 2005; Shan et al., 2008; Kim et al., 2009; Lim and Lee, 2009; Bueno Galaz et al., 2010; Lim et al., 2013). Therefore, the present study was conducted to evaluate the dietary choline requirement and its essentiality for parrot fish.

\section{MATERIALS AND METHODS}

\section{Experimental diets}

Formulation of the experimental diets is provided in
Table 1. A basal experimental diet was formulated and used as a control and three other diets were prepared by supplementing $500,1,000$, or $2,000 \mathrm{mg} / \mathrm{kg}$ choline (designated as Con, C500, C1000, and C2000, respectively). Another control diet without choline supplementation was prepared to contain $0.3 \%$ of 2-amino-2-methyl-1-propanol (AMP) as a choline biosynthesis inhibitor and regarded as positive control $\left(\mathrm{Con}^{+}\right)$. The analyzed choline concentrations of the experimental diets were 230 (Con), $230\left(\mathrm{Con}^{+}\right), 663$ (C500), 1,000 (C1000), and 1,554 (C2000) $\mathrm{mg} / \mathrm{kg}$ diet respectively. White fish meal (Suhyup Feed Co. Ltd., Uiryeong, Korea) and casein were used as dietary protein sources. To remove choline from fish meal, it was extracted two times with $70 \%$ aqueous ethanol solution (ethanol/water, 7/3, v/v) for $48 \mathrm{~h}$, and then dried using an electric fan at room temperature. The dietary ingredients were thoroughly mixed with squid liver oil and $30 \%$ distilled water in a mixer (NVM-14-2P, Busan, Korea). The wet dough was pelleted by a chopper machine (SMC-12, Kuposlice, Busan, Korea) at $4 \mathrm{~mm}$ of diameter. The diets were then freeze-dried at $-40^{\circ} \mathrm{C}$ for $24 \mathrm{~h}$, crushed into desirable particle sizes ( 1 to $3.0 \mathrm{~mm}$ ) and stored at $-45^{\circ} \mathrm{C}$ until used.

\section{Fish and feeding trial}

Juvenile parrot fish were transported from a private

Table 1. Formulation and proximate composition of the experimental diets ( $\%$ dry matter)

\begin{tabular}{|c|c|c|c|c|c|}
\hline & \multicolumn{5}{|c|}{ Diets } \\
\hline & Con & Con+ & $\mathrm{C} 500$ & $\mathrm{C} 1000$ & C2000 \\
\hline \multicolumn{6}{|l|}{ Ingredients } \\
\hline White fish meal (defatted $)^{1}$ & 56.0 & 56.0 & 56.0 & 56.0 & 56.0 \\
\hline Casein & 10.0 & 10.0 & 10.0 & 10.0 & 10.0 \\
\hline Dextrin (vitamin free) & 15.0 & 15.0 & 15.0 & 15.0 & 15.0 \\
\hline AMP & 0.0 & 0.3 & 0.0 & 0.0 & 0.0 \\
\hline Choline chloride & 0.0 & 0.0 & 0.05 & 0.1 & 0.2 \\
\hline Mineral $\operatorname{mix}^{2}$ & 1.0 & 1.0 & 1.0 & 1.0 & 1.0 \\
\hline Vitamin $\operatorname{mix}^{3}$ & 1.0 & 1.0 & 1.0 & 1.0 & 1.0 \\
\hline Squid liver oil & 14.0 & 14.0 & 14.0 & 14.0 & 14.0 \\
\hline $\mathrm{CMC}$ & 2.0 & 2.0 & 2.0 & 2.0 & 2.0 \\
\hline Cellulose & 1.0 & 0.7 & 0.95 & 0.9 & 0.8 \\
\hline \multicolumn{6}{|c|}{ Proximate composition (\%dry matter) } \\
\hline Moisture & 9.3 & 9.8 & 9.0 & 9.1 & 9.7 \\
\hline Protein & 45.1 & 45.6 & 44.8 & 45.3 & 45.9 \\
\hline Lipid & 16.9 & 17.1 & 17.4 & 16.7 & 17.0 \\
\hline Ash & 10.1 & 9.7 & 9.2 & 10.3 & 9.8 \\
\hline Analyzed choline $(\mathrm{mg} / \mathrm{kg})$ & $230 \pm 3$ & $230 \pm 35$ & $628 \pm 50$ & $1,027 \pm 38$ & $1,496 \pm 83$ \\
\hline
\end{tabular}

AMP, 2-amino-2-methyl-1 propanol; CMC, carboxymethyl cellulose.

Calculated based on the compositions of the ingredients used (NRC, 1993).

${ }^{1}$ White Fish meal was extracted with $70 \%$ aqueous ethanol (ethanol/water, 7/3) for $48 \mathrm{~h}$.

${ }^{2}$ Mineral premix (g/kg of mixture): $\mathrm{MgSO}_{4} 7 \mathrm{H}_{2} \mathrm{O}, 80.0 ; \mathrm{NaH}_{2} \mathrm{PO}_{4} 2 \mathrm{H}_{2} \mathrm{O}, 370.0 ; \mathrm{KCl}, 130.0$; Ferric citrate, 40.0; $\mathrm{ZnSO}_{4} 7 \mathrm{H}_{2} \mathrm{O}, 20.0$; Ca-lactate, 356.5; $\mathrm{CuCl}_{2}, 0.2 ; \mathrm{AlCl}_{3} \cdot 6 \mathrm{H}_{2} \mathrm{O}, 0.15 ; \mathrm{Na}_{2} \mathrm{Se}_{2} \mathrm{O}_{3}, 0.01 ; \mathrm{MnSO}_{4} \cdot \mathrm{H}_{2} \mathrm{O}, 2.0 ; \mathrm{CoCl}_{2} \cdot 6 \mathrm{H}_{2} \mathrm{O}, 1.0$.

${ }^{3}$ Vitamin premix (g/kg of mixture): L-ascorbic acid, 121.2; DL- $\alpha$ tocopheryl acetate, 18.8; thiamin hydrochloride, 2.7; riboflavin, 9.1; pyridoxine hydrochloride, 1.8; niacin, 36.4; Ca-D-pantothenate, 12.7; myo-inositol, 181.8; $\mathrm{D}$-biotin, 0.27; folic acid, 0.68; p-aminobenzoic acid, 18.2; menadione, 1.8; retinyl acetate, 0.73 ; cholecalciferol, 0.003 ; cyanocobalamin, 0.003 . 
hatchery (Chang-Hae Fisheries Co., Jeju-Island, Korea) to the Marine and Environmental Research Institute (Jeju National University, Jeju, Korea). The fish were fed a commercial diet for one month to become acclimated to the experimental facilities and conditions. At the end of the acclimation period, the fish (body weight, $8.8 \pm 0.01 \mathrm{~g}$ ) were randomly assigned to fifteen 150 -L polyvinyl circular tanks at a density of 25 fish per tank. The experiment was done in triplicates and the fish were fed at a rate of $4 \%$ body weight twice daily (8:00 and 18:00 h) for 12 wk. A flow-through system was used and the tanks were supplied with sand filtered seawater at a rate of $3 \mathrm{~L} / \mathrm{min}$ and aeration to maintain enough dissolved oxygen. The photoperiod was scheduled by $11: 13 \mathrm{~h}$ (light/dark) using fluorescent light. Water temperature ranged from $19^{\circ} \mathrm{C}$ to $25^{\circ} \mathrm{C}$ according to the seasonal changes. Salinity of the water was $32 \%$ to $34 \%$, dissolved oxygen ranged from 7.80 to $8.05 \mathrm{mg} / \mathrm{L}$, and the $\mathrm{pH}$ was maintained at $8.02 \pm 0.01$. The growth of fish was measured every two wk and feeding rate was adjusted accordingly. The fishes were fasted for $24 \mathrm{~h}$ prior to weighing or blood sampling. The tanks were routinely cleaned using sponge to prevent the growth of microflora. Experimental protocols followed the guidelines approved by the Animal Care and Use Committee of Jeju National University.

\section{Sample collection and analyses}

At the end of the feeding trial, all the fish in each tank were weighed and counted for calculation of growth performance and survival. Three fish per tank were sampled for measurement of liver lipid and choline concentrations and fatty acid composition. Also, another set of three fish per tank (9 fish per treatment) were randomly selected and anaesthetized with 2-phenoxyethanol (100 mg/L), and blood samples were taken from the caudal vein using non heparinized syringes. The samples were used for determination of respiratory burst and myeloperoxidase (MPO) activities. All the analyses were performed in Fish Feed and Nutrition Laboratory of Jeju National University (Jeju, Korea).

The liver lipid concentration was analyzed using the method of Folch et al. (1957). Choline concentration in the experimental diets and liver samples were measured using the choline/acetylcholine assay kit (Abcam, UK).

The liver lipid was extracted according to Folch et al. (1957). Fatty acid methyl esters (FAMEs) of liver lipids were prepared using acid-catalysed transesterification method (Metcalfe et al., 1961). The FAMEs were analyzed by gas chromatography (GC; HP 6890, Agilent, Wilmington, DE, USA) using an HP-88 column $(100 \mathrm{~m} \times 250 \mu \mathrm{m} \times 0.25$ $\mu \mathrm{m}$; Agilent, USA). The GC conditions were as follows: Injector and detector temperature was $260^{\circ} \mathrm{C}$; carrier gas, $\mathrm{H}_{2}$; and split ratio, 1/100. The programmed temperature was as follows: $140^{\circ} \mathrm{C}$ for $5 \mathrm{~min}$; increase of $4^{\circ} \mathrm{C} / \mathrm{min}$ to $230^{\circ} \mathrm{C}$; $230^{\circ} \mathrm{C}$ for $10 \mathrm{~min}$; increase of $3^{\circ} \mathrm{C} / \mathrm{min}$ to $240^{\circ} \mathrm{C}$; and $240^{\circ} \mathrm{C}$ for $10 \mathrm{~min}$. Peaks were identified by comparison of retention times with those of the corresponding standards of FAMEmix-37 (Supelco, Bellefonte, PA, USA). Fatty acids concentrations were expressed as percentage (w/w) of total FAMEs.

\section{Monitoring of non-specific immune responses}

Oxidative radical production by phagocytes during respiratory burst was measured through nitro-bluetetrazolium (NBT) assay described by Anderson and Siwicki (1995). Briefly, blood and NBT (0.2\%) (Sigma, St. Louis, MO, USA) were mixed in equal proportion $(1: 1)$ and incubated for $30 \mathrm{~min}$ at room temperature. Then $50 \mu \mathrm{L}$ was taken out and dispensed into glass tubes. One $\mathrm{ml}$ of dimethylformamide (Sigma, USA) was added and centrifuged at $2,000 \times \mathrm{g}$ for $5 \mathrm{~min}$. Finally, the optical density of supernatant was measured at $540 \mathrm{~nm}$ using a spectrophotometer (Genesys 10UV, Rochester, NY, USA). Dimethylformamide was used as the blank.

The MPO activity was measured according to Quade and Roth (1997). Briefly, $20 \mu \mathrm{L}$ of serum was diluted with Hanks balanced salt solution without $\mathrm{Ca}^{2+}$ or $\mathrm{Mg}^{2+}$ (SigmaAldrich, USA) in 96-well plates. Then, $35 \mu \mathrm{L}$ of 3,3',5,5'tetramethylbenzidine hydrochloride $(20 \mathrm{mM})$ (SigmaAldrich, USA) and $\mathrm{H}_{2} \mathrm{O}_{2}(5 \mathrm{mM})$ were added. The color change reaction was stopped after $2 \mathrm{~min}$ by adding $35 \mu \mathrm{L}$ of $4 \mathrm{M}$ sulfuric acid. Finally, the optical density was read at $450 \mathrm{~nm}$ in a microplate reader.

\section{Statistical analysis}

All experimental diets were assigned by a completely randomized design. Data were subjected to one-way analysis of variance (ANOVA) in SPSS version 11.0 (SPSS Inc., Chicago, IL, USA). The significant differences between group means were compared using Tukey's honestly significant difference at the $5 \%$ level of significance $(\mathrm{p}<0.05)$. Data are presented as mean \pm standard deviation. Percentage data were arcsine-transformed before the ANOVA analysis.

\section{RESULTS}

The results of fish growth performance and feed utilization are shown in Table 2. The results showed a significant decrease of growth performance in fish fed the $\mathrm{Con}^{+}$diet in comparison to the other groups. Also, a significant reduction in $\mathrm{FE}$ was observed in the group offered the $\mathrm{Con}^{+}$diet. No significant effects of choline supplementation were found on growth or feed utilization although numerically higher values were recorded for fish fed C1000 and C2000 diets compared to those fed the Con 
Table 2. Growth performance of parrot fish (initial body weight $8.80 \pm 0.01 \mathrm{~g}$ ) fed the five experimental diets for $12 \mathrm{wk}$

\begin{tabular}{lcccccc}
\hline \multirow{2}{*}{ Item } & \multicolumn{5}{c}{ Diets } & \multicolumn{2}{c}{ p value } \\
\cline { 2 - 5 } & Con & Con $^{+}$ & C500 & C1000 & C2000 & 0.000 \\
FBW & $58.1 \pm 1.09^{\mathrm{b}}$ & $48.8 \pm 1.52^{\mathrm{a}}$ & $58.0 \pm 0.80^{\mathrm{b}}$ & $60.9 \pm 0.95^{\mathrm{b}}$ & $59.5 \pm 0.75^{\mathrm{b}}$ & 0.000 \\
$\mathrm{WG}^{1}$ & $560 \pm 12.1^{\mathrm{b}}$ & $453 \pm 18.7^{\mathrm{a}}$ & $560 \pm 9.50^{\mathrm{b}}$ & $592 \pm 10.2^{\mathrm{b}}$ & $577 \pm 7.00^{\mathrm{b}}$ & 0.000 \\
$\mathrm{SGR}^{2}$ & $2.25 \pm 0.02^{\mathrm{b}}$ & $2.03 \pm 0.04^{\mathrm{a}}$ & $2.25 \pm 0.02^{\mathrm{b}}$ & $2.30 \pm 0.02^{\mathrm{b}}$ & $2.28 \pm 0.01^{\mathrm{b}}$ & 0.830 \\
$\mathrm{FI}^{3}$ & $60.7 \pm 2.78$ & $60.7 \pm 1.42$ & $59.9 \pm 1.44$ & $61.4 \pm 0.18$ & $61.5 \pm 2.41$ & 0.000 \\
$\mathrm{FE}^{4}$ & $0.90 \pm 0.03^{\mathrm{a}}$ & $0.73 \pm 0.04^{\mathrm{b}}$ & $0.91 \pm 0.02^{\mathrm{a}}$ & $0.93 \pm 0.02^{\mathrm{a}}$ & $0.91 \pm 0.04^{\mathrm{a}}$ & 0.699 \\
Survival & $97.3 \pm 4.62$ & $97.3 \pm 2.31$ & $98.7 \pm 2.32$ & $96.0 \pm 0.00$ & $96.0 \pm 4.00$ &
\end{tabular}

FBW, final body weight; WG, weight gain; SGR, specific growth rate; FI, feed intake; FE, feed efficiency; SD, standard deviation.

${ }^{1} \mathrm{WG}(\%)=100 \times($ final body weight - initial body weight $) /$ initial body weight.

${ }^{2} \mathrm{SGR}(\%)=100 \times[\ln ($ final body weight $)-\ln ($ initial body weight $)] / \mathrm{d}$.

${ }^{3} \mathrm{FI}(\mathrm{g} / \mathrm{fish})=$ total dry feed fed $(\mathrm{g}) / \mathrm{fish}$

${ }^{4} \mathrm{FE}=$ wet weight gain $(\mathrm{g}) / \mathrm{dry}$ feed given $(\mathrm{g})$.

Mean values of triplicate groups are presented as mean \pm SD. Values in the raw having different superscript letters are significantly different $(p<0.05)$. The lack of a superscript letter indicates no significant differences among treatments.

Table 3. Non-specific immune response of parrot fish fed the five experimental diets for $12 \mathrm{wk}$

\begin{tabular}{|c|c|c|c|c|c|c|}
\hline \multirow{2}{*}{ Item } & \multicolumn{5}{|c|}{ Diets } & \multirow{2}{*}{$\mathrm{p}$ value } \\
\hline & Con & $\mathrm{Con}^{+}$ & C500 & $\mathrm{C} 1000$ & C2000 & \\
\hline NBT (absorbance) & $1.85 \pm 0.16$ & $1.79 \pm 0.09$ & $1.81 \pm 0.06$ & $1.85 \pm 0.05$ & $1.80 \pm 0.04$ & 0.842 \\
\hline MPO (absorbance) & $1.56 \pm 0.11$ & $1.50 \pm 0.01$ & $1.61 \pm 0.37$ & $1.62 \pm 0.01$ & $1.69 \pm 0.05$ & 0.732 \\
\hline
\end{tabular}

NBT, nitro-blue-tetrazolium; MPO, myeloperoxidase; SD, standard deviation.

Mean values of triplicate groups are presented as mean \pm SD. The lack of a superscript letter indicates no significant differences among treatments.

diet. Feed intake did not significantly differ among the experimental groups. The survival rate varied from $96 \%$ to $98 \%$ without any significant differences.

Innate immune parameters including NBT and MPO activities did not significantly differ among dietary treatments (Table 3).

The highest liver lipid concentration was observed in fish fed $\mathrm{Con}^{+}$diet, but no significant differences were detected (Figure 1). The liver choline concentration showed a positive correlation with dietary choline level and inversely correlated with liver lipid content. Liver fatty acid composition of fish fed the diets is shown in Table 4. Fish fed the $\mathrm{Con}^{+}$diet exhibited significantly higher accumulation of linoleic acid, eicosapentaenoic acid (EPA) and docosahexaenoic acid (DHA) in the liver compared to the other fish groups. An opposed tendency was observed for palmitic acid, where significantly lower value was obtained in fish fed the $\mathrm{Con}^{+}$diet than those fed $\mathrm{C} 1000$ diet.

\section{DISCUSSION}

In this study a reduced growth performance was obtained when AMP was included in the diet. The AMP is one of the choline antagonists which have been demonstrated to slow down the choline biosynthesis through the inhibition of $S$-adenosyl-methionine-dependent methylation and results in choline deficiency symptoms. Rumsey (1991) reported that it can effectively block the choline biosynthesis in rainbow trout. The significant reduction in weight gain and FE of fish by AMP supplementation in this study indicated that it can effectively inhibit de novo choline synthesis in parrot fish.
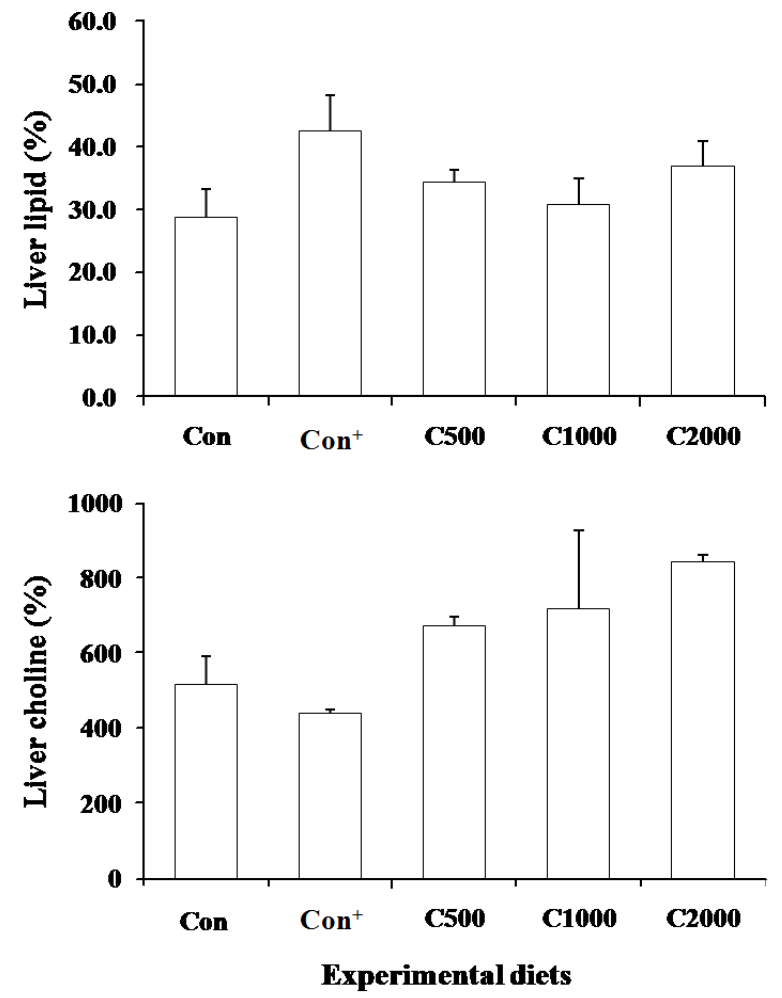

Figure 1. Liver lipid and choline concentration of juvenile parrot fish fed the experimental diets for $12 \mathrm{wk}$. 
Table 4. Liver fatty acids composition (\% total fatty acids) of parrot fish fed the five experimental diets for $12 \mathrm{wk}$

\begin{tabular}{|c|c|c|c|c|c|c|}
\hline & \multicolumn{5}{|c|}{ Diets } & \multirow{2}{*}{$\mathrm{p}$ value } \\
\hline & Con & $\mathrm{Con}^{+}$ & C500 & C1000 & C2000 & \\
\hline $\bar{C} 14: 0$ & $6.62 \pm 0.20$ & $5.83 \pm 0.27$ & $6.18 \pm 0.50$ & $6.67 \pm 0.90$ & $6.48 \pm 0.38$ & 0.318 \\
\hline C16:0 & $38.3 \pm 1.46^{\mathrm{ab}}$ & $34.2 \pm 1.11^{\mathrm{a}}$ & $38.3 \pm 2.45^{\mathrm{ab}}$ & $42.0 \pm 0.62^{\mathrm{b}}$ & $38.8 \pm 3.12^{\mathrm{ab}}$ & 0.011 \\
\hline C18:0 & $5.24 \pm 0.05$ & $4.47 \pm 1.12$ & $5.86 \pm 0.06$ & $5.59 \pm 0.24$ & $6.02 \pm 0.13$ & 0.069 \\
\hline C18:1n-9 & $7.78 \pm 0.97$ & $7.59 \pm 1.02$ & $8.73 \pm 0.74$ & $8.37 \pm 0.95$ & $8.80 \pm 0.38$ & 0.495 \\
\hline C18:2n-6 & $12.9 \pm 0.29^{\mathrm{ab}}$ & $15.2 \pm 1.89^{\mathrm{b}}$ & $11.4 \pm 0.01^{\mathrm{a}}$ & $11.4 \pm 1.25^{\mathrm{a}}$ & $11.6 \pm 0.70^{\mathrm{a}}$ & 0.011 \\
\hline C18:3n-3 & $4.87 \pm 0.51$ & $4.32 \pm 0.18$ & $5.21 \pm 0.60$ & $4.39 \pm 0.67$ & $4.50 \pm 0.61$ & 0.462 \\
\hline C22:1n-9 & $1.77 \pm 0.20$ & $1.17 \pm 0.22$ & $1.95 \pm 0.18$ & $1.80 \pm 0.25$ & $1.93 \pm 0.17$ & 0.062 \\
\hline C20:3n-3 & $2.18 \pm 0.06$ & $2.25 \pm 0.32$ & $2.04 \pm 0.13$ & $1.92 \pm 0.28$ & $2.01 \pm 0.07$ & 0.385 \\
\hline$C 20: 5 n-3$ & $9.03 \pm 0.11^{\mathrm{a}}$ & $10.6 \pm 0.60^{b}$ & $8.61 \pm 0.31^{\mathrm{a}}$ & $8.81 \pm 0.48^{\mathrm{a}}$ & $9.46 \pm 0.50^{\mathrm{ab}}$ & 0.004 \\
\hline$C 22: 6 n-3$ & $17.1 \pm 0.46^{\mathrm{a}}$ & $23.5 \pm 1.97^{b}$ & $16.7 \pm 1.90^{\mathrm{a}}$ & $18.3 \pm 0.14^{\mathrm{a}}$ & $19.2 \pm 2.38^{\mathrm{ab}}$ & 0.005 \\
\hline
\end{tabular}

Mean values of triplicate groups are presented as mean \pm standard deviation. Values in the row having different superscript letters are significantly different $(\mathrm{p}<0.05)$. The lack of a superscript letter indicates no significant differences among treatments.

Methionine, as one of the sulfur amino acids, is a wellknown nutritional factor that influences choline requirement. Choline is synthesized by the sequential methylation of phosphatidylethanolamine in several animal species including fish (NRC, 1993). In this regard, methionine is involved in choline synthesis by enhancing the availability of S-adenosylmethionine which serves as methyl donor (Bender, 1992; NRC, 1993). In the present study, the Con diet contained $1.84 \%$ methionine which is probably higher than the requirement level for parrot fish. Our results showed that the fish fed Con diet had significantly higher growth than those fed AMP containing diet, and the values were comparable to those of fish fed the choline supplemented diets. This may indicate the de novo synthesis of choline in parrot fish. The strong endogenous choline synthesis has also been earlier observed in channel catfish (Zhang and Wilson, 1999), while it has been shown that a dietary source of choline is required for rainbow trout (Rumsey, 1991), hybrid striped bass (Griffin et al., 1994), yellow perch (Twibell and Brown, 2000), hybrid tilapia (Shiau and Lo, 2000) and cobia (Mai et al., 2009) when dietary sulfur amino acids concentration are not provided in excess level.

The results of previous studies on hybrid striped bass (Griffin et al., 1994), yellow perch (Twibell and Brown, 2000), hybrid tilapia (Shiau and Lo, 2000) and cobia (Mai et al., 2009) showed that the optimal choline requirement level ranges from 500 to $1,000 \mathrm{mg} / \mathrm{kg}$ diet when choline chloride was used as choline source. In the present study the basal diet contained around $230 \mathrm{mg} / \mathrm{kg}$ choline and additional supplementation levels did not result in improvement of growth performance, indicating that the basal level of choline meets the requirements of parrot fish. The dietary content of precursors such as methionine or betaine, age/size, growth rate and species specific differences have been regarded as effective factors on response to dietary supplementation of choline (Wilson and
Poe, 1988; Rumsey, 1991; Griffin et al., 1994).

Liver lipid content has been used as an indicator for evaluation of choline status in animals (McDowell, 2000; Halver, 2002). Choline as a lipotropic factor involves in metabolism and mobilization of liver lipids and prevents the abnormal accumulation of fat and development of fatty liver. It is involved in the synthesis of phospholipids such as PC, as an integral part of lipoproteins which are important in the extracellular transport of lipids in the blood and lymph (Tocher, 1995; 2003). Apparently, PC is the predominant phospholipid class in fish lipoproteins (Nelson and Shore, 1974; Chapman, 1980). The increment of liver lipid in the presence of AMP in this study may be attributed to the reduction of $\mathrm{PC}$ as a result of impaired lipoprotein secretion and subsequent accumulation of triglycerides. Choline supplementation to the basal diet did not influence the liver lipid content which is in agreement with earlier studies on rainbow trout and yellow perch when they were fed the diets with different levels of choline (Rumsey, 1991; Twibell and Brown, 2000). However, liver lipid content of channel catfish and hybrid striped bass significantly decreased at increased dietary choline levels (Griffin et al., 1994; Zhang and Wilson, 1999). In contrast, studies on red drum and hybrid tilapia have shown increased levels of liver lipid in response to dietary choline supplementation (Craig and Gatlin, 1996; Shiau and Lo, 2000).

In this study liver choline concentration of parrot fish was increased in a dose dependent manner. Similar results were observed in channel catfish (Zhang and Wilson, 1999) and cobia (Mai et al., 2009). Apparently, based on liver choline levels, the dietary choline requirement of parrot fish is much higher than the value based on weight gain. Mai et al. (2009) declared that this may be due to higher choline requirement for physiological functions than for growth.

Considering the fact that fatty acids are structural components of phospholipid and neutral lipid molecules which undergo altered metabolism during choline 
deficiency, we examined the fatty acid composition of fish liver in order to gain further insight as to the lipotropic action of choline. Interestingly, our results showed the higher accumulation of linoleic acid, EPA and DHA in the liver when the fish were provided with AMP containing diet. There is no earlier report on the effect of dietary choline on fish liver fatty acid composition. Eric et al. (1965) could not find any differences in fatty acid composition of liver between choline-deprived and choline fed rats. Watkins et al. (2003) used quantitative lipid metabolite profiling to characterize lipid metabolism in PEMT-deficient and wild mice fed diets containing varying concentrations of choline. Their results showed higher accumulation of free fatty acids in liver of mice fed the choline deficient diet compared to those fed choline supplemented diet. Also, they found that PEMT activity affects the flux of lipid between liver and plasma and the delivery of essential fatty acids to blood and peripheral tissues; where PEMT-deficient mice had substantially diminished concentrations of DHA and arachidonic acid in plasma. This finding clearly shows that impairment of endogenous choline synthesis results in accumulation of fatty acids in the liver which is in agreement with our results.

Dietary lipotropes including choline are involved in several metabolic pathways and play an important role in cellular metabolism via the regulatory effects on the transfer of one-carbon moieties which are used for DNA synthesis. Instant availability of nucleotide predecessors is especially important in lymphatic system. Therefore, deficiency of these cofactors can negatively affect the immune function and disease resistance (Nauss and Newberne, 1981). Courrèges et al. (2003) demonstrated that choline dietary deficiency produces an impairment of the immune response in rats. Their results showed that choline deficiency results in diminution of Th2/Th1 response which can lead to reduced host response to antigens. However, there is no available study on the effect of dietary choline level on fish immune response. Fishes mostly rely on non-specific immune system than specific immune system (Anderson, 1992). The non-specific immune system includes both cellular and humoral responses of which respiratory burst and MPO activities are related to the humoral immune response. During the respiratory burst reactive oxygen species are produced by phagocytes and the activity can be measured through the NBT assay. The MPO is an important enzyme with microbactericidal activity and is one of the potent agents in killing pathogens. In the present study, however, no significant differences were found among all the fish groups. The non-specific immune response lasts for a short duration and disappears with the time due to the lack of immunologic memory in this type of immunity (Anderson, 1992). Furthermore, each of innate immune factors may differently respond to the dietary additives
(Secombes, 1996). Therefore, further complementary studies are needed to examine the effects of dietary choline on innate immunity of fish.

In conclusion, our results showed that choline concentration of $230 \mathrm{mg} / \mathrm{kg}$ diet largely meets parrotfish requirement for growth and normal lipid metabolism, and that the additional choline supplementation in diet is not necessary for the juvenile parrot fish. The fish seems to synthesize enough choline for its normal growth and metabolism. Further studies are required in the future to estimate the exact choline requirement of the species.

\section{ACKNOWLEDGMENTS}

This study was supported by the National Research Foundation of Korea (NRF) grant funded by the Korean Government (MEST) (No. 2011-0015925).

\section{REFERENCES}

Anderson, D. P. 1992. Immunostimulants, adjuvants, and vaccine carriers in fish: applications to aquaculture. Annu. Rev. Fish. Dis. 2:281-307.

Anderson, D. P. and A. K. Siwicki. 1995. Basic hematology and serology for fish health programs. In: Diseases in Asian aquaculture II (Eds. M. Shariff, J. R. Arthur, and R. P. Subasinghe). Fish health section, Asian Fisheries Society, Manila, Phillipines. pp. 185-202.

Bender, D. A. 1992. Nutritional Biochemistry of the Vitamins. Cambridge University Press, New York, USA.

Bueno Galaz, G., S. S. Kim, and K. J. Lee. 2010. Effects of different dietary vitamin $\mathrm{E}$ levels on growth performance, nonspecific immune responses, and disease resistance against Vibrio anguillarum in parrot fish (Oplegnathus fasciatus). Asian Australas. J. Anim. Sci. 23:916-923.

Chapman, M. J. 1980. Animal lipoproteins: Chemistry, structure, and comparative aspects. J. Lipid Res. 21:789-853.

Combs, G. F. 1992. The Vitamins: Fundamental Aspects in Nutrition and Health. Academic Press, New York, USA.

Courrèges, M. C., F. Benecia, A. Uceda, and A. J. Monserrat. 2003. Effect of dietary choline deficiency on immunocompetence in Wistar rats. Nutr. Res. 23: 519-526.

Craig, S. R. and D. M. Gatlin. 1996. Dietary choline requirement of juvenile red drum Sciaenops ocellatus. J. Nutr. 126:16961700.

Eric, A., J. R. Glende, and W. E. Cornatzer. 1965. Fatty acid composition of rat liver lipids during choline deficiency. J. Nutr. 86:178-186.

Folch, J., M. Lees, and S. G. H. Stanley. 1957. A simple method for the isolation and purification of total lipides from animal tissues. J. Biol. Chem. 226:497-509.

Griffin, M. E., K. A. Wilson, M. R. White, and P. B. Brown. 1994. Dietary choline requirement of juvenile hybrid striped bass. J. Nutr. 124:1685-1689.

Halver, J. E. 2002. The vitamins, In: Fish Nutrition (Eds. J. E. Halver, and R. W. Hardy). 3rd edn. Academic Press, San Diego, 
CA, USA. pp. 61-140.

Ketola, H. G. 1976. Choline metabolism and nutritional requirement of lake trout (Salvelinus namaycush). J. Anim. Sci. 43:474-477.

Kim, S. S., G. Bueno Galaz, M. A. Pham, J. W. Jang, D. H. Oh, I. K. Yeo, and K. J. Lee. 2009. Effects of dietary Supplementation of a Meju, Fermented Soybean Meal, and Aspergillus oryzae for Juvenile Parrot Fish (Oplegnathus fasciatus). Asian Australas. J. Anim. Sci. 22:849-856.

Lim, S. J. and K. J. Lee. 2009. Partial replacement of fish meal by cottonseed meal and soybean meal with iron and phytase supplementation for parrot fish Oplegnathus fasciatus. Aqauculture 290:283-289.

Lim, S. J., D. H. Oh, S. Khosravi, J. H. Cha, S. H. Park, K. W. Kim, and K. J. Lee. 2013. Taurine is an essential nutrient for juvenile parrot fish Oplegnathus fasciatus. Aquaculture 414415:274-279.

Mai, K., L. Xiao, Q. Ai, W. Wang, W. Xu, W. Zhang, Z. Liufu, and M. Ren. 2009. Dietary choline requirement for juvenile cobia, Rachycentron canadum. Aquaculture 289:124-128.

McDowell, L. R. 2000. Vitamins in Animal and Human Nutrition. $2^{\text {nd }}$ edn. Academic Press, New York, USA.

Metcalfe, L. D., A. A. Schmitz, and J. R. Pelka. 1966. Rapid preparation of fatty acid esters from lipids for gas chromatographic analysis. Anal. Chem. 38:514-515.

Nam, Y. K., Y. S. Cho, B. N. Choi, K. H. Kim, S. K. Kim, and D. S. Kim. 2005. Alteration of antioxidant enzymes at the mRNA level during short-term starvation of rockbream Oplegnathus fasciatus. Fish. Sci. 71:1385-1387.

Nauss, K. M. and P. M. Newberne. 1981. Effects of dietary folate, vitamin B12 and methionine/choline on immune function. In: Diet and Resistance to Disease (Eds. M. Phillips, and A. Baetz). Plenum Publishing Corp, New York, USA. pp. 63-91.

Nelson, G. J. and V. G. Shore. 1974. Characterization of the serum high density lipoproteins and apolipoproteins of pink salmon. J. Biol. Chem. 249:536-542.

NRC. 1993. National Research Council Nutrient Requirements of Fish. National Academy Press, Washington, DC, USA.

Ogino, C., N. Uki, T. Watanabe, Z. lida, and K. Ando. 1970. B vitamin requirements of carp. 4. Requirement for choline. Bull. Jpn. Soc. Sci. Fish. 36:1140-1146.
Quade, M. J. and J. A. Roth. 1997. A rapid, direct assay to measure degranulation of bovine neutrophil primary granules. Vet. Immunol. Immunopathol. 58:239-248.

Rumsey, G. L. 1991. Choline-betaine requirements of rainbow trout Oncorhynchus mykiss. Aquaculture 95:107-116.

Secombes, C. J. 1996. The non-specific immune system: Cellular defenses. In: The Fish Immune System (Eds. G. Iwama, T. Nakanishi). Academic Press, San Diego, CA, USA. pp. 63-103.

Shan, X., H. Quan, and S. Dou. 2008. Effects of delayed first feeding on growth and survival of rock bream Oplegnathus fasciatus larvae. Aquaculture 277:14-23.

Shiau, S. Y. and P. S. Lo. 2000. Dietary choline requirements of juvenile hybrid tilapia, Oreochromis niloticus $\times O$. aureus. J. Nutr. 130:100-103.

Tocher, D. R. 1995. Glycerophospholipid metabolism. In: Biochemistry and Molecular Biology of Fishes, Metabolic and Adaptational Biochemistry, vol. 4. (Eds. P. W. Hochachka and T. P. Mommsen). Elsevier Press, Amsterdam, The Netherlands. pp. 119-157.

Tocher, D. R. 2003. Metabolism and functions of lipids and fatty acids in teleost fish. Rev. Fish. Sci. 11:107-184.

Twibell, R. G. and P. B. Brown. 2000. Dietary choline requirement of juvenile yellow perch (Perca flavescens). J. Nutr. 130:95-99.

Wang, X., K. W. Kim, S. C. Bai, M. D. Huh, and B. Y. Cho. 2003. Effects of the different levels of dietary vitamin $\mathrm{C}$ on growth and tissue ascorbic acid changes in parrot fish (Oplegnathus fasciatus). Aquaculture 215:203-211.

Watkins, S. M., X. Zhu, and S. H. Zeisel. 2003. Phosphatidylethanolamine-N-methyltransferase activity and dietary choline regulate liver-plasma lipid flux and essential fatty acid metabolism in mice. J. Nutr. 133:3386-3391.

Wauben, P. M. and P. E. Wainwright. 1999. The influence of neonatal nutrition on behavioral development: A critical appraisal. Nutr. Rev. 57:35-44.

Wilson, R. P. and W. E. Poe. 1988. Choline nutrition of fingerling channel catfish. Aquaculture 68:65-71.

Zeisel, S. H. 1990. Choline deficiency. J. Nutr. Biochem. 1:332344

Zhang, Z. and R. P. Wilson. 1999. Reevaluation of the choline requirement of fingerling channel catfish (Ictalurus punctatus) and determination of the availability of choline in common feed ingredients. Aquaculture 180:89-98. 